\title{
NOTES OF THE TYPES OF AESHNA PUNCTATA MARTIN, 1908 (ODONATA, AESHNIDAE)
}

ANGELO B. M. MACHADO

\section{ABSTRACT}

The type series of Aeshna punctata Martin, 1908 was examined and some inconsistent points in the original description were elucidated. A lectotype was designated, redescribed and illustrated. The two females originally referred to this species actually belong to the Mexican species Aeshna jalapensis Williamson, 1908. Thus, A. punctata should be dropped from the faunistic list of Mexico.

\section{INTRODUCTION}

In 1908 Martin described Aeshna punctata based on male and female specimens from Brazil and Mexico respectively. The description includes two pictures of the appendages of a male (fig. 51) based on a specimen in the Selys collection. These pictures were later reproduced in plate 2 of Martin (1911) which has also a colour picture of a male A. punctata. A careful analysis of Martin's descriptions and pictures of A. punctata revealed the following inconsistent points:

1. In the description (page 54) the abdominal segment 10 is described as "avec un mamelon pointu dorsal", while in the key (page 82) it is reported without a strong tooth. Figure 51, however, shows a very prominent dorsal tubercle on segment 10 .

2. Martin's description gives the abdomen of the males as $60-64 \mathrm{~mm}$ long and that of the female as $48-50 \mathrm{~mm}$. The figures for the male abdomen are so much larger than those for the females that Calvert (1956) suggested the possibility of a lapsus calami.

3. In the colour picture (plate 2) of Martin (1911) the pale antehumeral stripes are larger and abdominal segments $7-9$ have more pale spots than stated in the description.

4. The figure of the wings in Martin (1911) shows 4 rows of cells between the fork of IR3 while the description mentions only 3.

These inconsistent aspects of Martin's descriptions and figures of $A$. punctata raise the possibility that his type-series might contain more than one species and (or) that his pictures might not be accurate. In order to check these points we have studied the types of $A$. punctata during a quick visit to Selys' collection in Brusse's and in Martin's collection in the Paris Museum. The types in the Paris Museum were brought to our laboratory in Belo Horizonte where a redescription of the specimen selected as the lectotype was performed. A clear definition of what is Aeshna punctata Martin, 1908 was deemed necessary since Martin's description could be applied to at least two different, although closely related species, one of which is now being described (Machado, 1985).

\section{THE TYPES OF AESHNA PUNCTATA}

The original description of Martin (1911) says: Types $\hat{\sigma}$ et $q$ coll. René Martin. Coll. Selys: 1 o. Habitat: Mexique, Brésil. At the request of Dr. Calvert, Dr. Erich Schmidt examined these types in 1951. The situation of the type specimens as observed by him (reported in Calvert, 1956) coincides

Departamento de Morfologia, Instituto de Ciências Biológicas, Universidade Federal de Minas Gerais, Belo Horizonte, MG. 
basically with our own observations. The type series consists of 3 males and 2 females. One male (specimen 1), is in Selys' collection at the "Institut Royal de Sciences Naturelles" at Brussels. Two males and two females (specimens 2-5) are in a single box in Martin's collection at the "Muséum National d'Histoire Naturelle" at Paris. The labels of the type specimens are as follows:

Specimen 1. (in Selys' collection). White label: Eschna punctata Selys $\hat{\sigma}$ - Brésil/125. (written possibily in Selys' handwriting). Green label, printed "type" - P. Br. (most probably means Paul Borchgrave).

Specimen 2. White labei: A. punctata Type (written presumably in Martin's handwriting). White label, printed in red: TYPE. Green collection label: Museum Paris Coll. R. Martin 1920. Green locality label: Espirito Santo, Brasil ex coll. Frühstorfer. (A male in good condition).

Specimen 3. A male from Espirito Santo. The details of the labels were not recorded.

Specimen 4. Green label: A. punctata M. type - Mexique (written in a handwriting slightly different from that of specimen 1). White label printed in red: TYPE. Green collection label: Museum Paris coll. R, Martin 1920. (female lacking the distal half of right forewing, apex of left forewing and left appendage).

Specimen 5. Labeled like specimen 4. A female lacking apex of right hindwing, with the abdomen compressed and lacking both appendages.

An analysis of these specimens revealed the following:

1. The two males in Martin's collection are no doubt conspecific.

2. The appendages of the male specimen in Selys collection are slightly different from those of the males in Martin's collection. Therefore this specimen may not be conspecific with those in Martin's collection.

3. The two females belong to a different species determined as Aeshna (Schizuraeschna) jalapensis Williamson, 1908, a common species from Mexico. In view of this $A$. punctata should be dropped from the faunistic list of Mexico.

4. The mid-dorsal tooth on the 10th segment in figure 51 by Martin (1911) is exaggerated and does not fit any specimen in the type series. Except for this character the figure corresponds well to the male in Selys' collection.

5. The colored figures of Martin in "Genera Insectorum" are inaccurate and do not agree with the type series.

6. The two sketches of abdominal segment 6 made by Schmidt for Calvert (1956) have been transposed: the one reported to belong to the male in Selys' collection (specimen 1) actually belongs to a male in Martin's collection (specimen 2).

Both Dr. Schmidt and Dr. Calvert regarded the specimen now referred to as $\mathrm{n} .^{\circ} 2$ in Martin's collection as the holotype and the remaining specimens as paratypes. Their reasons for so doing are based on the fact that this specimen is the only one that has the word "type" written in the label with Martin's handwriting. Howewer, in the light of the present rules of nomenclature all the specimens in the type series of $A$. punctata should be regarded as syntypes, since Martin did not designate a holotype in the original description. In view of this we have designated specimen 2 in Martin's collection as the lectotype of $A$. punctata. Since the females described by Martin (1908) are not $A$. punctata the first description of the female of this species is that of Calvert (1956).

\section{DESCRIPTION OF THE LECTOTYPE OF A. PUNCTATA}

HEAD (figs. 1-2): Labium reddish brown. Base of the mandible yellow with black triangular spot in the angle between the eye and the clypeus (fig. 1). Labrum yellow, distal margin narrowly edged with brown, a black line on the clypeo-labral suture. Anteclypeus yellow: clypeus pale blue, a dark line in the frontoclypeal suture enlarged into a triangular spot toward 
the eye (fig. 1). Anterior (vertical) surface of frons pale blue turning into brown in its upper part: a transverse black line in the crest separating the anterior from the dorsal surface of the frons, continuous with the head of the dark $T$ spot (figs. 1-2). Dorsal surface of frons pale blue, the black T-spot (fig. 2) with a stem of uniform width $(1,3 \mathrm{~mm})$, bordered laterally by a narrow yellow stripe $0.3 \mathrm{~mm}$ wide. A black transversal basal stripe embracing the vertex, the ocelli and the bases of the antennae, connected with the fronto-clypeal black line along the eye margin of the frons (figs. 1-2). Vertex yellowish; occiput triangular, yellowish-brown, its angles black, hind margin slightly concave. Rear of the head dark-brown.

PTEROTHORAX (fig. 3): reddish brown with dark areas surrounding the lower extremities of the meso- and metepimeral stripes and at the upper part of the mesoepisternum adjacent to the humeral suture. A yellowish antehumeral stripe on each mesepisternum, $2.9 \mathrm{~mm}$ long, maximum width $0.75 \mathrm{~mm}$ at the midlength, anterior end almost pointed, not reaching the anterior margin of the slerite by $0.5 \mathrm{~mm}$; hind end rounded $1.5 \mathrm{~mm}$ distant from the carina of the antealar sinus. Mesepimeral stripe (fig. 3) yellow, $7.5 \mathrm{~mm}$ long and $0.6 \mathrm{~mm}$ wide at its lower third. Metepimeral stripe (fig. 3) yellow with pale blue tinges at its upper third, $6 \mathrm{~mm}$ long and $0.7 \mathrm{~mm}$ wide at its lower third. Legs with femora reddish-brown: tibiae brown; tarsi black, all spines of the legs dark. Wings hyaline, sligthly smokey on the apex, venation black, costa anteriorly pale-brown from base to nodus; pterostigma brown, membranule dark brown, whitish on the anterior fourth. Venation as in figures 9 and 10. The right hind wring shows an anomaly which probably resulted from an impairment of expansion during emergence.

ABDOMEN: Dorsal surface reddish brown with pale yellowish markings on all segments. Lateral carinae of all segments dark. Ventral surface of tergites reddish brown. Sternites black. Treatment with $90^{\circ}$ alcohol or acetone and careful adjustment of the illumination allowed the visualization of the pale abdominal markings of each segment (fig. 5). Their description follow (nomenclature according to Walker, 1912): AD absent (faded?) on all segments except 3 , where it is very small. MD absent on 1, fused with each other on mid-dorsal line on 2; small transverse and separate on 3-6, not traceable with certainty on 7-8. PD small and fused with each other on 1; large, fused with each other and with ML and PL on 2; separated from each other on $3-9$, the separation very narrow on $3-4$; AL absent on 1 , extending from the anterior to the transverse carina on 2-3; forming an oblique narrow stripe bordering the transverse carina anteriorly on $4-7$; absent on 8-10. ML absent on 1, fused with PL on 2, present as a spot of moderate size on 3-7, very small on 8 , apparently absent on 9 , present on 10 . On $5-6, \mathrm{ML}$ is adjacent to the lateral carina, being distinctly separated from it in the remaining segments. PL present on 1, fused with ML on 2, present on 3, absent (or faded) on 4-7, present on 8-10.

Auricles with two distal teeth (fig. 6). Structures of the genital fossa shown in figure 6. Anterior lamina cleft almost to the level of the hind end of the sternum of abdominal segment 1 (fig. 6); its spine slightly curved in ventral view, in profile their apices do not project ventral to the margin of the genital fossa, being partly concealed by this margin on the left side. Hamular processes as in fig. 6. In profile (fig. 4) the margins of the genital fossa are produced ventrally to form the genital lobe at about $40^{\circ}$ with the lateral margin of the fossa. The genital lobe projects ventrally 1.35 $\mathrm{mm}$ beyond the lateral margin of segment 2 and its length measured along the prolonged margin of segment 2 is $2.45 \mathrm{~mm}$. The margin and lateral surface of the genital lobe are provided with spinules (figs. 4, 6). Dorsum of abdominal segment 10 with a mid-dorsal tooth and, on each side of it, two successively lower and blunter carinae (figs. 7, 8). Superior appendages (figs. 7-8) brown with the margins of the superior carinae and the apical spine black. Height of the anteapical arch of the superior carina $0.55 \mathrm{~mm}$. Inferior appendages (figs. 7-8) brown with the margins black. 

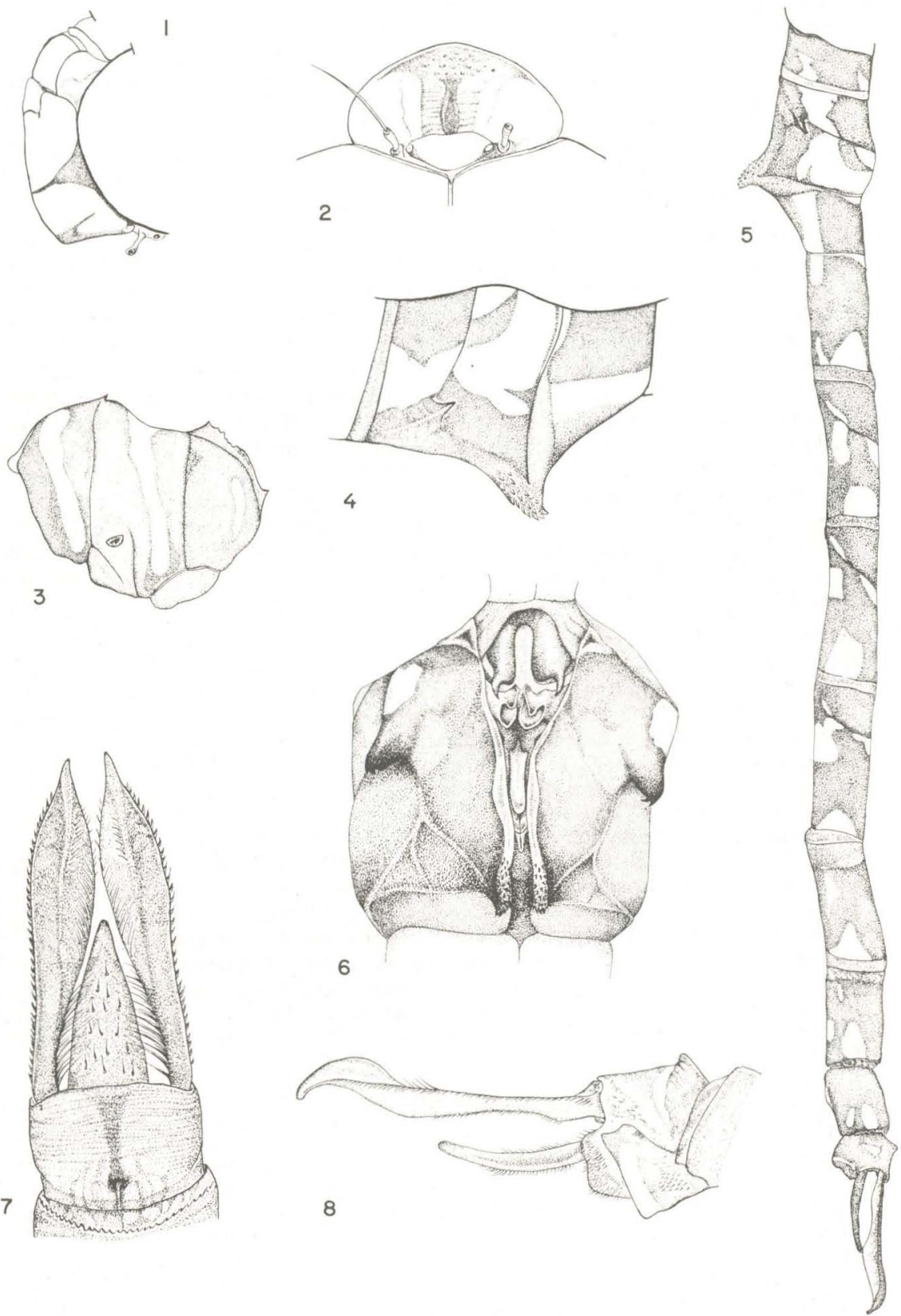

Aeshna punctata Martin, 1908: 1, head, right lateral view; 2, frons, dorsal view; 3, pterothoracic color pattern, right lateral view; 4, 2nd abdominal segment, lateral view, showing genital lobe; 5, abdominal color pattern, left lateral view; 6, 2nd abdominal segment, ventral view; 7, abdominal segment 10 and appendage, dorsal view; 8, same, lateral view. 
Vol. 2(6), 1985

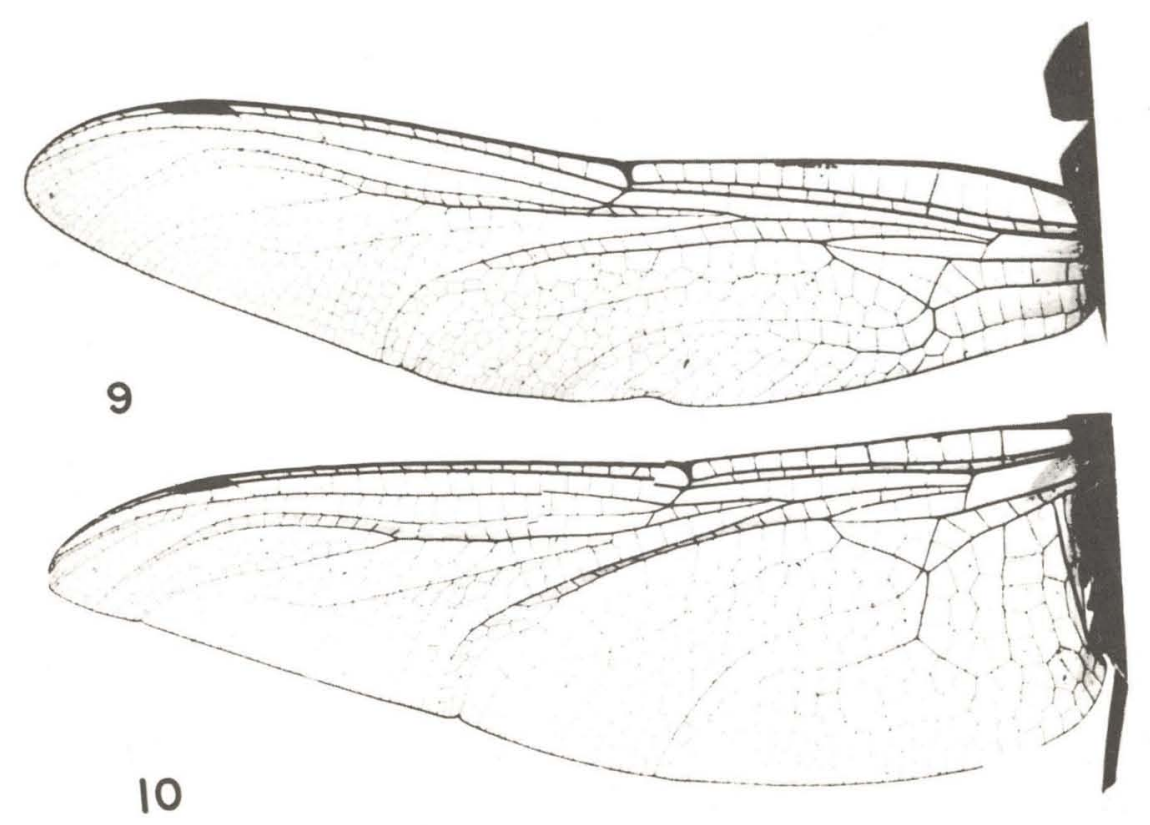

Aeshna punctata Martin, 1908: 9, left fore wing; 10, left hind wing. 


\section{DIMENSIONS:}

Abdomen (exclusive of the appendages): $54.5 \mathrm{~mm}$.

Superior appendages: $6.0 \mathrm{~mm}$.

Inferior appendages: $3.3 \mathrm{~mm}$.

Hind wing (left): $49.5 \mathrm{~mm}$.

Front wings: $52.0 \mathrm{~mm}$.

Pterostigma of front wing: $2.8 \mathrm{~mm}$.

Pterostigma of hind wing: $2.7 \mathrm{~mm}$.

\section{ACKNOWLEDGMENTS}

This research was supported by FINEP, and CNPq provided the funds that allowed my visit to Selys' and Martin's collections. I would like to express my gratitude to Prof. Jean Legrand and Prof. G. Desmoulin for the opportunity to study the type specimens of $A$. punctata in Martin collection in Paris and Selys' collection in Brussels. To the entomologist Maria Aparecida Vulcano I am deeply indebted for the drawings that illustrate this article and also thank Dr. Antonio Cesar R. Leite for help in obtaining the photograph of the wings.

\section{REFERENCES}

Calvert, P. P., 1956. The neotropical species of the "subgenus Aeshna" sensu Selysii 1883 (Odonata). Mem. Am. ent. Soc. 15: v + 251, 47 pls.

Machado, A. B. M., 1985. Description of Aeshna (Hesperaeschna) eduardoi Machado, 1984 from the mountains of Minas Gerais, Brazil (Anisoptera Aeshnidae). Odonatologica, in press.

Martin, R., 1908. Collections Zoologiques du Baron Edmond de Selys-Longchamps. Catalogue systematique et descriptif Fasc. XVIII, Aeschnines pp. $1-84$, pls. I-II.

Martin, R., 1911. Odonata, Fam. Aeschnidae in Witsman, P. Genera Insectorum 115: $1-34$, pls. I-VI.

Walker, E. M., 1912. The North American dragonflies of the genus Aeshna. Univ. Toronto Studies Biol. Series. pp. 1-213, pls. 1-28. 